\title{
474110 - COMPARISON OF GLIDSCOPE® SUCCESS RATES BY EXPERTS IN PATIENTS WITH WITH NORMAL AND DIFFICULT AIRWAYS
}

\author{
Hwan Joo, md, Elizabeth Mathieson, MD, Viren Naik, FRCPC, Lyndon Siu, MD, \\ Deven Chandra, MD, Mathew Bould, MB ChB \\ Anesthesia, St. Michael's Hospital, Toronto, ON, Canada
}

Introduction: The Glidescope ${ }^{\circledR}$ can be used for both routine and difficult airways. However, the efficacy of the Glidescope ${ }^{\circledR}$ may be lower in patients with difficult airways. Therefore, before attempting to electively induce anesthesia for endotracheal intubation in patients with potential or documented difficult airways, data is required on the likelihood of successful intubation when compared to patients with normal airways. Methods: After institutional ethics approval, a prospective database of all patients intubated with Glidescope ${ }^{\circledR}$ was created in 2006. Consent was obtained from all anesthesiologists in the department at the beginning of the study. Both patient characteristics and Glidescope ${ }^{\circledR}$ user characteristics were recorded at the time of the intubation. Of the 750 Glidescope intubations in the database, 191 Glidescope intubations met the criteria of having "an expert" Glidescope ${ }^{\circledR}$ user. This criteria was based on a previous CAS abstract which showed that success rates reach a maximal plateau after 30 previous Glidescope ${ }^{\circledR}$ uses.(1) Patients were grouped into 3 possible groups: 1) predicted "normal" airways; 2) "potentially difficult" airways based on preoperative examination; or 3) "documented difficult" airways from previous anesthetics records or failed direct laryngoscopy during the current anesthetic induction

Results: In the normal group, 93\% (65/70) were successfully intubated during the first attempt. In the potentially difficult group it was 83\% (66/80) and in the documented difficult group it was $80 \%$ (33/41). The success rates between the groups were trending towards a difference at $\mathrm{p}=0.08$. However, there was no statistical difference. The median Cormack and Lehane laryngeal view was $1(1,1)$ in the normal group, $1(1,2)$ in the potentially difficult group and $2(1,3)$ in the documented difficult group. Both potentially difficult and documented difficult group had a view that was worse than the normal group $(\mathrm{p}<0.05)$. We can postulate that the trend towards decreased success rates for patients with abnormal airways was due to worsening laryngeal views.

Discussion: The results of our study show that there is a trend towards decreased success rates with the Glidescope ${ }^{\circledR}$ in patients with potential or documented difficult airways. However, there was no statistical difference. First attempt success rates were high in all groups. The overall success rates may be even higher if multiple attempts are performed. With first attempt success rate of $80 \%$ for documented difficult airway, Glidescope ${ }^{\circledR}$ may be an effective tool for use during the management of unanticipated difficult airways. However, the elective use of the Glidescope ${ }^{\circledR}$ for patients with potential or documented difficult airways is an individual decision based on the results of the current and previous studies, the anesthesiologist's experience with the Glidescope ${ }^{\circledR}$ and overall patient characteristics.

References: 1.Mathieson et. al. CAS abstract 2007 
Success and Failures

\begin{tabular}{|c|c|c|}
\hline Normal Success & Possibly Difficult & Difficult \\
65 & 66 & 33 \\
\hline Failure & Failure & Failure \\
5 & 14 & 8 \\
\hline
\end{tabular}

